\title{
Tierra, reformas y recursos naturales: una perspectiva desde el sur de México
}

\author{
Sergio Francisco Rosas Salas
}

Luis Alberto Arrioja Díaz Viruell
y Carlos Sánchez Silva (EDS.), 2012

Conflictos por la tierra en Oaxaca. De las reformas borbónicas a la reforma agraria

El Colegio de Michoacán, Universidad Autónoma Benito Juárez de Oaxaca, Zamora, 264 pp.

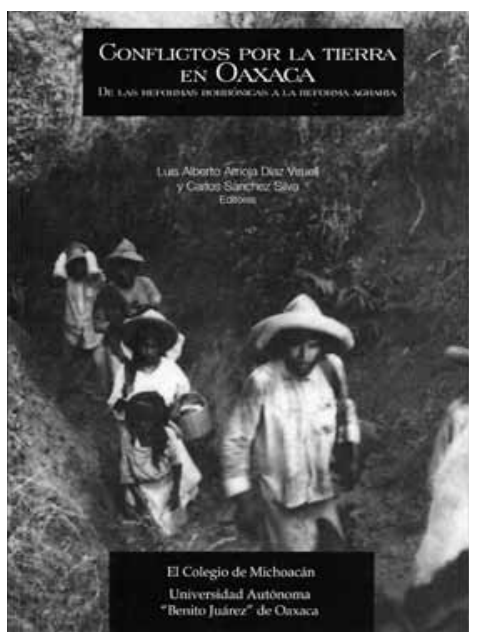

$\mathrm{E}$

1 reciente libro de Luis Alberto Arrioja y Carlos Sánchez analiza las luchas por la tierra y los recursos naturales en Oaxaca desde una mirada histórica. Destaca la multiplicidad de actores y el papel activo de los pueblos campesinos en dos procesos fundamentales de la historia del campo mexicano: las reformas borbónicas y la reforma agraria. A partir de ocho capítulos, Conflictos por la tierra en Oaxaca... estudia problemas

\section{Region, Reforms and Natural Resources: An Outlook from the South of Mexico}

Sergio Francisco Rosas Salas: Centro de Estudios de las Tradiciones, El Colegio de Michoacán, Zamora, Michoacán, México rosass@colmich.edu.mx

Desacatos, núm. 44, enero-abril 2014, pp. 219-222 entrecruzados en las transiciones de la Monarquía a la República y del Porfiriato a la Revolución. Una lectura en conjunto revela continuidades entre el siglo XVIII y el $\mathrm{xx}$ que vale la pena destacar: el papel activo y pragmático de los pueblos en conflictos agrarios de larga duración, las confrontaciones entre pueblos vecinos — no sólo entre pueblos y haciendas, que por lo demás también existen y se mencionan en el texto- por el control de los recursos naturales y una constante fragmentación territorial que se incrementó hasta alcanzar su corolario con la reforma agraria, que en Oaxaca tuvo su auge durante el cardenismo. 
La primera parte del libro, dedicada a los conflictos agrarios durante las reformas borbónicas y los primeros años de la República, está compuesta por cuatro capítulos. En el primero de ellos, de Arrioja Díaz Viruell y Sánchez Silva, se tiene como objetivo analizar las reformas que Borbones y gobiernos republicanos implementaron en la estructura agraria de Oaxaca. El punto de partida es un elemento que el lector no debe perder de vista a lo largo del trabajo: el predominio de las repúblicas de indios como propietarias de la tierra en la entidad. Éstas, sin embargo, se encontraron desde el siglo XVIII bajo el embate de la política anticorporativa de la Corona, impulsada aun más en la carta gaditana, que continuó durante el periodo republicano en un proceso que no concluiría sino hasta la Ley Lerdo de 1856. De este modo, los autores enmarcan la discusión general del libro en el proyecto anticorporativo propio de las políticas ilustradas y liberales entre la segunda mitad del siglo xviII y 1856 y su impacto local en un medio marcado por el amplio predominio de la propiedad indígena. Esta mirada entre lo global y lo local, entre lo jurídico y lo social, es uno de los aportes valiosos de esta obra. Así, persevera en una renovación historiográfica que se ocupa del impacto de las políticas agrarias en Oaxaca, como el reciente libro del mismo Arrioja Díaz Viruell (2011) para el caso de Villa Alta o el de Edgar Mendoza García (2011) en lo que corresponde a los pueblos chocholtecos de la Mixteca Alta. En esta línea, el trabajo de Huemac Escalona es un estudio de caso en torno a los conflictos por el tablón de Jaltepec entre Candoyoc y San Pedro Acatlán, pueblos mixes, en el cual se destaca que las comunidades indígenas fueron adaptando su discurso ante las coyunturas políticas con el objetivo de alcanzar el dominio legal y efectivo de las tierras en disputa.

Los trabajos de Luis J. García Ruiz y Laura Machuca examinan un problema novedoso para la comprensión de los problemas agrarios: el papel de los mestizos $\mathrm{y}$ afrodescendientes en los conflictos por la tierra en los años previos a la insurgencia. García Ruiz hace notar la presencia de mulatos y pardos en diversas regiones del territorio oaxaqueño y subraya su papel central en la producción azucarera. A partir de varios casos a lo largo y ancho de la geografía local, el autor sostiene que éstos, como los mestizos, se identificaron más con los blancos que con las repúblicas de indios, por lo que actuaron como grupo frente a ellas en problemas de tenencia de la tierra, pues los blancos les permitían en última instancia un mayor acceso a la tierra que los indígenas, como lo constata el caso bien analizado de Teotitlán del Camino. Por supuesto, este acceso no era siempre en propiedad, sino más usualmente como fuerza de trabajo o arrendamiento. Respecto de los mestizos, García Ruiz resalta el hecho de que su presencia y la de los españoles, aunada a la política anticorporativa ilustrada, hizo que en la Mixteca Alta, sobre todo en Huajuapan, se privilegiara la propiedad particular sobre la corporativa de las repúblicas de indios al determinarse en 1784 que aquella población era tanto de indios como de españoles. García Ruiz concluye que la convivencia de indios, negros y españoles durante los siglos coloniales fue una fuente de conflictos que a la postre modificó el patrón de tenencia de la tierra en algunas regiones de Oaxaca.

Por su parte, Machuca Gallegos analiza los conflictos por la tierra en los Petapas, en el Istmo de Tehuantepec, durante el siglo xIX. Este caso resulta valioso porque demuestra, a diferencia de lo planteado por García Ruiz, que en el Istmo la lucha de negros y mulatos por la tierra los llevó a asimilarse a los pueblos de indios de la región. Lejos de representar una afinidad de raza, esta asimilación ejemplifica el pragmatismo de la población de raíz africana en su lucha por el dominio de los recursos naturales, la cual consiguió con 
éxito hacerse de tierras en el barrio de La Soledad, integrado originalmente al pueblo de Santa María Petapas. De esta forma, tanto García Ruiz como Machuca Gallegos incorporan la pluralidad étnica como un elemento más para tomar en consideración en el estudio de los conflictos agrarios en los últimos años del Antiguo Régimen.

La segunda parte del libro, compuesta también por cuatro capítulos, se ocupa de la tenencia de la tierra entre el Porfiriato y la Revolución. En conjunto, estos trabajos subrayan la continuidad de la lógica jurídica anticorporativa en los años del liberalismo triunfante, una mayor presencia de las haciendas en los conflictos agrarios durante el Porfiriato y la perenne lucha activa de los pueblos en la defensa o búsqueda de los recursos naturales disponibles. Una primera visión de conjunto advierte las profundas desigualdades del campo oaxaqueño, como puede apreciarse en el texto de Anselmo Arellanes. En un trabajo sugerente, Margarita Menegus y Yair Gerardo Hernández analizan los obstáculos para la transformación de la estructura de la propiedad agraria en la Mixteca, en particular en el caso de Huajuapan. Los autores encuentran que bajo el amparo de la Ley Lerdo al menos 68 poblaciones de terrazgueros compraron las tierras de los excaciques y llegaron así a ser pequeños propietarios de sus parcelas. En ese sentido, en aquella región sí se consiguió uno de los más preciados objetivos liberales: formar pequeños propietarios agrícolas. Ello trajo consigo la creación de sociedades agrícolas, personalidades jurídicas que con bienes y trabajo comunes explotaron la tierra. Si bien no todas tuvieron éxito, el caso de Chazumba, fundada en 1871, muestra que las hubo que llegaron a beneficiar a los pequeños propietarios. Tal fue el éxito, que algunos de ellos se opusieron a la reforma agraria cardenista y buscaron obtener tierra de aquella sociedad como dotación ejidal. Sin embargo, la pequeña propiedad conformada en el último tercio del siglo XIX determinó el modelo de reparto agrario que se siguió en la Mixteca, en la cual predominó la dotación con tierras cerriles y un continuo conflicto entre pequeños propietarios y ejidatarios. Sin duda, este artículo abre un ámbito para la investigación en distintas geografías, particularmente del centro de México, donde la historiografía agraria de la reforma liberal está aún centrada en las haciendas: la historia de las sociedades agrícolas de fines del siglo xIx. Estudios como éste vistos desde Oaxaca permitirían contrastar esta experiencia regional de la reforma liberal en el ámbito rural con otros ámbitos de México, como el caso mejor conocido de San Luis Potosí (Escobar y Gutiérrez, 2009).

Arrioja Díaz Viruell analiza, a partir del caso del conflicto entre Juan Guelache y San Pedro Teococuilco, la forma en que los pueblos campesinos oaxaqueños utilizaron la memoria y la historia documental como parte de la lucha y defensa de tierras que consideraban propias. A partir de la búsqueda de títulos en el Archivo General y Público de la Nación de 1912 por parte de una comisión de habitantes de Guelache enviada por su Ayuntamiento, el autor muestra bien que los campesinos indígenas fueron actores capaces de rescatar la memoria documental de sus pueblos y de emplearla como un arma legal en la reivindicación de sus derechos agrarios. Así, presenta a los indígenas como actores activos en el marco jurídico constitucional, que exigía los títulos de propiedad para reconocer y garantizar el dominio legal de un territorio. En ello seguían, asimismo, una tradición arraigada en los siglos coloniales: acudir a las autoridades superiores, en litigio, y buscar la justicia para su causa. Sin duda, esta vuelta de tuerca respecto de los conflictos legales en los años de la República hace del tema de la memoria y de los títulos de propiedad un protagonista, y no sólo una fuente de los conflictos agrarios locales. Al mismo tiempo, revela en los campesinos 
una memoria utilitarista, pragmática y cambiante de acuerdo con las circunstancias que exigía la legislación del momento, siempre con el objetivo último de asegurarse la posesión de las tierras. El trabajo descubre otra veta de investigación: el de la construcción y los usos de la memoria - documentalcampesina y el papel de ésta como norma legitimadora de derechos en la República liberal e incluso en el México

revolucionario.

El libro cierra con un capítulo de Juan Hugo Sánchez García, dedicado a la importancia del agua en los conflictos agrarios de Oaxaca. Al incorporarse a una joven pero sólida renovación

historiográfica en torno a los usos sociales del agua, el trabajo de Sánchez García abre una veta novedosa de investigación para la historiografía regional a partir del caso de los Valles Centrales. Así, destaca el impacto de la legislación de 1888 en la modificación de la normatividad jurídica estatal, visible en la Ley de Aguas de Oaxaca de 1905, por medio de la cual inició la centralización de recursos hidráulicos por parte del gobierno estatal, una visión de la legislación no ensayada hasta ahora y que pone de manifiesto la fuerza del derecho consuetudinario en la normativa local. En un marco de escasez, el aumento en la demanda de agua por la diversificación de las actividades productivas y el incremento de actores interesados en el recurso hídrico en el distrito de Etla derivaron en una intensificación de los conflictos por el agua, que el autor analiza a partir de la pugna entre los pueblos de Magdalena Apasco y San Juan del Estado y la hacienda de San Isidro Catano. Si bien ésta consiguió acaparar el agua durante el Porfiriato, su dominio del líquido se perdió con el reparto agrario, que se concretó en 1927. A decir de Sánchez García, durante la reforma agraria el agua fue un elemento central en la búsqueda de tierras, un aspecto que ofrece - como ha mostrado Rocío Castañeda (2004) para el Valle de Santa Rosalía en Chihuahua - una nueva visión de este proceso definitorio de la propiedad agraria en el siglo xx mexicano. En suma, Conflictos por la tierra en Oaxaca... consigue unir dos reformas centrales en la historia de Oaxaca y del resto del país. Al mismo tiempo, pone de nuevo en el centro de la discusión historiográfica la investigación en torno a la propiedad rural en las transiciones del antiguo al nuevo régimen y abre nuevas vetas de investigación en un tema ya conocido por nuestra historiografía y en una historiografía regional con una amplia y firme tradición en México.

\section{BIBLIOGRAFÍA}

Arrioja Díaz Viruell, Luis Alberto, 2011, Pueblos de indios y tierras comunales: Villa Alta, Oaxaca: 1742-1856, El Colegio de Michoacán, Zamora, México.

Castañeda González, Rocío, 2004, Irrigación y reforma agraria: las comunidades de riego en el valle de Santa Rosalía, Chihuahua 1920-1945, Centro de Investigaciones y Estudios Superiores en Antropología Social, Comisión Nacional del Agua, México.

Escobar Ohmstede, Antonio y Ana María Gutiérrez Rivas (coords.), 2009, Entretejiendo el mundo rural en el oriente de San Luis Potosí, siglos XIX y XX, El Colegio de San Luis, San Luis Potosí.

Mendoza García, J. Edgar, 2011, Municipios, cofradías y tierras comunales. Los pueblos chocholtecos de Oaxaca en el siglo $X I X$, Centro de Investigaciones y Estudios Superiores en Antropología Social, Universidad Autónoma Benito Juárez de Oaxaca, Universidad Autónoma Metropolitana-Azcapotzalco, México. 